\title{
APOSENTADORIA: como professores vivenciam este momento?
}

\section{RESUMO:}

O presente artigo buscou compreender as implicações que a aposentadoria causa na vida de professores, levando em conta o significado que a aposentadoria representa à estes, considerando os pontos de maior mudança após a aposentadoria, bem como os aspectos positivos e negativos causados pela aposentadoria na percepção dos sujeitos da pesquisa. Para tanto, foi realizada uma pesquisa qualitativa caracterizada como exploratória e descritiva com professores aposentados por mais de dois anos, com idade entre 58 e 66 anos, através de entrevistas individuais, com roteiros semiestruturados. A análise dos dados foi por meio da análise de conteúdo de Bardin (2011). Entre os principais resultados, destaca-se o significado de "liberdade" que a aposentadoria representa, a rotina como maior mudança e flexibilidade de horários dentre os pontos positivos e a falta dos alunos como aspecto negativo, contudo, pode-se perceber que a aposentadoria possibilitou e contribuiu para que os professores pudessem desfrutar de momentos de lazer, dedicando cuidado à família e realizando seus anseios e vontades.

Palavras-chave: Aposentadoria. Trabalho. Professores.

\section{RETIREMENT: How do teachers experience this moment?}

\section{ABSTRACT:}

This article aimed at understanding the implications of retirement in the life of elementary and high school teachers, taking into considerationthe meaning of retirement to them, considering the greatest changing elements after retirement, as well as the positive and negative aspects caused by retirement in the perception of the research subjects. Thus, a qualitative investigation was carried out, being characterized as exploratory and descriptive, done withteachers who were retired for more than two years; aged between 58 and 66, by using individual semi-structured interviews. Data analysis was carried out through Bardin's Content Analysis (2011). Amongthe main results, we can emphasize the meaning of freedom brought by retirement, the routine with great changes and flexible schedule as positive aspects and the lack of students as the negative aspect. However, it is possible to notice that retirement contributed and enabled teachers to enjoy leisure moments, dedicating care to family and satisfying their wishes and desires which could not be accomplished before, due to their work routine.

Keywords: Retirement; Work; Teachers.

(1) Bacharel do Curso de Psicologia da Universidade do Oeste de Santa Catarina UNOESC. cristiane.conrado@yahoo.com.br

(2) Professora do Curso de Psicologia da Universidade do Oeste de Santa Catarina UNOESC. michele.lucas@unoesc.edu.br 


\section{INTRODUÇÃO}

Diante do envelhecimento da população brasileira e a maior longevidade das pessoas idosas que conservam-se em boas condições físicas, fazem tarefas diárias e contribuem com suas famílias, surgiu o interesse em pesquisar sobre como professores aposentados vivenciam este momento, ante as alterações físicas e psicológicas que ocorrem na vida do indivíduo que encerra sua carreira no mundo do trabalho para aposentar-se gerando implicações na sua rotina.

Nesta etapa, não existem mais obrigações relacionadas à horários, avaliações, diários de classe e planejamento, contudo, seu círculo social pode tornar-se reduzido. Para alguns professores pode ser um momento desejado e esperado enquanto para outros pode se configurar em um momento de rompimento e isolamento, por isso, quando essa ocasião se aproxima e se concretiza, novas preocupações passam a surgir.

Diferentes sensações podem percorrer na nova rotina do indivíduo, ou seja, alegria, prazer, flexibilidade de horários e sentimento de dever cumprido, porém também podem surgir aborrecimentos, tristeza, isolamento e estranheza gerados pelo sentimento de inatividade, pois a migração de trabalhador ativo e provedor para aposentado acaba muitas vezes o categorizando como inativo, rompendo assim uma trajetória de atividades, bem como de papéis ocupados durante 30 anos ou mais.

Deste modo, a aposentadoria traz consigo a interrupção das atividades profissionais, e, preencher o tempo livre torna-se um desafio, pois suas preocupações agora estão direcionadas a sentir-se útil e ativo, o que pode afetar a sua qualidade de vida e toda sua dinâmica. $E$, em contrapartida o fato de poder desfrutar da companhia da família, ter flexibilidade de horários e gozar de seus momentos de lazer alteram significativamente o ritmo de sua nova rotina diária. Por isso, é importante estar preparado para este momento e, ter em mente que o que se espera muitas vezes pode não ocorrer e que novos desafios surgirão na nova configuração como aposentado.

\section{ENVELHECIMENTO}

A população idosa tem aumentado expressivamente nos últimos anos, com isso uma parcela crescente da população brasileira vem alcançando e desfrutando sua vida por mais tempo em decorrência do aumento da expectativa de vida e do acelerado envelhecimento populacional do país nas últimas décadas (NÉRI, 2004).

O envelhecimento é um processo inevitável onde cada pessoa envelhece no seu ritmo, para alguns esse processo acontece mais precoce e para outros demora mais, o que difere são as questões individuais de cada ser humano. Sendo assim, o envelhecimento se caracteriza por mudanças físicas em todo o organismo do indivíduo, alterando suas funções e trazendo mudanças nos seus comportamentos, percepções, sentimentos, pensamentos, ações e reações (SPIRDUSO, 2005).

Porém, Ferrari (1999) diz que a velhice não pode ser definida somente pela cronologia, mas sim pelas características anatômicas, funcionais, psicológicas e também pelas condições sociais dos indivíduos, uma vez que existem diferentes idades biológicas, as quais são distintas em indivíduos com a mesma idade cronológica, pois o envelhecimento é um processo subjetivo que ocorre de acordo com a realidade do indivíduo.

O envelhecimento impõe algumas limitações as quais se agravam com o tempo, porém as peculiaridades exclusivas de cada indivíduo permanecem, ou seja, calma, experiência, maturidade e a expectativa de viver diferenciam os seres humanos em todas as fases do ciclo vital. "Portanto, a velhice é hoje considerada uma fase de desenvolvimento humano e não mais um período de perdas e incapacidades" (FERRARI, 1999, p. 198). 
Assim, o envelhecimento pode trazer consigo crises de identidade, provocadas pela falta de papel social, alterações nos papéis tanto na família, no trabalho, quanto na sociedade, deste modo, aos poucos vai se adequando à novos papéis, diversas perdas relacionadas desde a situação econômica ao poder de decisão, perda de parentes, amigos, independência e autonomia, a diminuição dos contatos sociais e a aposentadoria que afeta diretamente o indivíduo que por vezes sente-se isolado, sem rumo e deprimido (ZIMERMAN, 2000).

Desta forma, Debetir (2011) entende que a crise de identidade pessoal inclui a mudança dos papéis antes exercidos pelo indivíduo na sociedade e posteriormente a aposentadoria converte-se em outro indivíduo com algumas restrições financeiras afetando o consumo, além disso, a forma com que o aposentado é tratado pela sociedade Ihe atribui características negativas.

Dentre estas questões, quando o sujeito se afasta da sua rotina laboral aposentando-se, e percebendo-se sem seu trabalho, o qual realizou durante toda sua vida, tal sensação pode vir a Ihe causar tristeza, dor e até sofrimento, mesmo tendo mais tempo para si e podendo desfrutar de momentos de lazer, esse desligamento juntamente com a ruptura do vínculo empregatício é marcado pelo início de uma nova fase. Tendo em vista a importância dispensada à vivência laboral cabe entender a conotação que o trabalho exerce na vida dos indivíduos.

\section{TRABALHO}

Os estudos acerca do trabalho foram iniciados no final do século XIX por Frederic Taylor no movimento da Administração Científica, onde o trabalho era visto como um processo e não somente como um caso isolado (CAMBOIM, et al., 2011). O trabalho se refere à ligação entre o homem e o meio, ou seja, segundo Marx (2004, p. 36) "antes de tudo, o trabalho é um processo entre o homem e a natureza, um processo em que o homem, por sua própria ação, media, regula e controla seu metabolismo com a natureza. Ele mesmo se defronta com a matéria natural como uma força natural", desta forma, o trabalho é essencial ao ser humano, uma vez que possibilita a sobrevivência e sua relação com tudo e todos que o rodeiam (MARX, 2004).

O trabalho dá sentido à vida humana, pois o decorrer da vida é baseado no trabalho, o qual visa atender as necessidades básicas de sobrevivência e também a auto-estima e a realização pessoal de cada um, no entanto, o mundo está envelhecendo e com o aumento da expectativa de vida tornou-se um desafio garantir a qualidade de vida à quem está em transição para a aposentadoria, ou seja, em média após 30 anos de trabalho os indivíduos se vêm em uma nova fase (ZANELLI; SILVA; SOARES, 2010).

As imagens e as ideias vinculadas ao conceito de trabalho sofreram muitas alterações ao longo da história, visto que a "avaliação do sentido e do lugar do trabalho humano sai do extremo da desvalorização, da atividade considerada como inferior - portanto, obrigação dos subalternos -, no contexto da pré-modernidade" (MOREIRA, 2011, p. 543).

Na modernidade o trabalho alcança um lugar de valor, de algo que define tanto a identidade quanto a existência de cada sujeito, assim, na contemporaneidade o trabalho passa a ter um lugar privilegiado na vida das pessoas, além de garantir a sobrevivência (MOREIRA, 2011). Frente ao destaque que o trabalho e a profissão exercem na vida dos indivíduos incumbe uma conjuntura em torno da carreira profissional, bem como seu significado e suas fases a partir da concepção de Schein.

\section{CARREIRA}

De acordo com Schein (1996) a palavra carreira é utilizada de diversas formas e possui 
várias conotações, ou seja, seguir uma carreira pode se referir a um indivíduo com uma profissão ou a uma vida profissional em ascensão, ainda pode referir-se a maneira que a vida profissional se desenvolve ao longo do tempo. A carreira pode ser interna quando diz respeito a forma como cada um vê seu trabalho, pois cada indivíduo tem uma visão acerca do seu trabalho, bem como a função que este desempenha em sua vida, já a carreira externa referese as etapas exigidas por uma profissão para que progrida no trabalho (SCHEIN, 1996).

Schein (1996) apresenta as principais fases da carreira, uma vez que o indivíduo percebe a carreira constituída de diversas etapas as quais são reconhecidas tanto pelo indivíduo quanto pela sociedade, contudo o tempo dispensado em cada etapa difere-se de acordo com a profissão e com o sujeito que a desempenha.

Deste modo, as fases da carreira descritas por Schein (1996) iniciam com o crescimento, a fantasia e a exploração e esta associada a infância e a pré-adolescência, onde a profissão é apenas parte de pensamentos, nesta fase o indivíduo inicia o processo educacional, a segunda fase diz respeito a educação e ao treinamento, ou seja, a profissão escolhida vai dizer o tempo de estudo que é necessário para o exercício efetivo da profissão.

Com relação a terceira fase ou ingresso ao mundo profissional, esta é uma etapa de adaptação, de conhecimento da realidade prática, sendo que o principal aprendizado começa a evoluir pois aqui são testadas suas aptidões, objetivos e valores. A quarta fase condiz com o treinamento básico e a socialização esta fase é a principal fonte de aprendizado, o profissional se vê diante de suas escolhas, bem como se deve ou não continuar com a profissão (SCHEIN, 1996).

A quinta fase trata da admissão do indivíduo como membro, surge a auto-imagem do sujeito como profissional, e os objetivos e valores começam a definir-se por meio de situações desafiadoras onde as escolhas devem ser feitas, o indivíduo percebe seus pontos fracos e fortes. A sexta fase esta relacionada a estabilização no emprego e a permanência como membro, ou seja, nos primeiros dez anos de carreira, grande parte das organizações e ocupações sugerem se o indivíduo pode ter um futuro a longo prazo. "A estabilidade é formal ou simbolicamente assegurada com a ressalva de que ela só existirá enquanto o emprego existir" (SCHEIN, 1996, p. 23).

Schein (1996, p. 25) traz na sétima fase a crise do meio da carreira e reavaliação, pois há evidencias de que os indivíduos passam por questionamentos referentes a sua escolha profissional e ao seu futuro, segundo o autor esta etapa pode ser traumática, já, a oitava fase refere-se ao avanço, recomeço ou estabilização, onde a reavaliação leva a decisões sobre a continuidade da carreira ou sua interrupção, a nona fase trata do desligamento, ou seja, o indivíduo diminui o ritmo de suas atividades e começa a refletir acerca da aposentadoria e organiza-se para esta etapa, contudo, "alguns lidam com uma possível aposentadoria por meio de uma veemente negação, continuando com as atividades normalmente e evitando a todo custo tentativas de outras pessoas para ajudá-los com os preparativos para a nova fase".

A décima fase refere-se à aposentadoria, estando ou não o indivíduo preparado para este momento e o que ocorre com a auto-imagem profissional difere de indivíduo para indivíduo, ou seja, para alguns a aposentadoria é traumática, prejudicando a saúde física e psicológica resultando na morte prematura do indivíduo (SCHEIN, 1996).

Além disso, aptidões, objetivos e valores interligam-se, pois, os indivíduos tendem a se aperfeiçoar em algo que valorizam e que são motivados a praticar, aprendem a valorizar e serem motivados por aquilo que fazem bem, desta forma, aprendem gradualmente a evitar o que não realizam bem (SCHEIN, 1996).

A carreira pode ser considerada como uma construção pessoal de significados e um meio social de organizar o conhecimento com base no trabalho, por isso, a carreira não é estática e 
momentânea, além de não ser determinada pela empresa, neste sentido, o trabalhador interage com outras pessoas da mesma forma que interage com sociedade e demais instituições onde está inserido (MAGALHÃES; BENDASSOLLI, 2013).

No entanto, quando um indivíduo se vê avaliado como incapacitado pela idade percebese que este sujeito já não é mais dono de sua carreira, por isso muitos tentam e buscam encontrar estratégias para enfrentar o dia de encerrar a carreira, pois tudo que praticou, inventou e investiu, perde-se em meio ao que a sociedade definiu, ou seja, que este profissional deve/necessita ceder seu espaço para novos trabalhadores aposentando-se (MUTCHNIK; TREVISAN, 2009).

Deste modo, cabe adentrar na questão da aposentadoria, diante da pressão que este momento pode causar em indivíduos que não estão preparados para esta fase ou até mesmo para entender o que a aposentadoria gera nos indivíduos. Diante do destaque que o trabalho exerce na vida dos indivíduos incumbe uma conjuntura com a categoria profissional dos professores, ou seja, a docência.

\section{A PROFISSÃO DOCENTE}

De acordo com alguns estudos realizados pela Organização das Nações Unidas para a educação, a ciência e a cultura, ao traçar informações sobre quem são os professores que atuam no ensino fundamental e no ensino médio defrontaram-se com o papel atribuído ao professor, fato que é discutido por pesquisadores de todo o mundo (UNESCO, 2004).

Neste sentido, o trabalho docente exige domínio cognitivo, instrumental, socialização e vivência profissional para que a construção da identidade profissional ocorra, envolvem-se neste processo de constituição "elementos emocionais, relacionais e simbólicos que permitem que um indivíduo se considere e viva como um professor e assuma, assim, subjetivamente e objetivamente, o fato de fazer carreira no magistério" (TARDIF, RAYMOND, 2000, p. 239).

Destarte, o professor é o profissional que deve estar sempre buscando e ajustando sua didática de acordo com a realidade do momento, além disso, o professor necessita "[...] de uma cultura geral mais ampliada, capacidade de aprender a aprender, competência para saber agir na sala de aula, habilidades comunicativas, domínio da linguagem informacional, saber usar os meios de comunicação e articular as aulas com as mídias e multimídias" (LIBÂNEO, 2003, p. 10).

Com relação à carreira dos professores, Huberman (1992) lista várias questões, ou seja, crises, acontecimentos, percursos, momento histórico, satisfação com a profissão, escolhas, opções, prudência, enfim, "o que é que distingue, ao longo das carreiras, os professores que chegam ao fim carregados de sofrimento daqueles que o fazem com serenidade?" (HUBERMAN, 1992, p. 36).

Ribeiro e Smeha (2009) afirmam que no percurso docente, o professor busca reconhecimento profissional diante de sua contribuição na formação de alunos, vivendo abarrotados de responsabilidades e cobranças, tendo, que enfrentar obstáculos ao longo do exercício profissional e apesar disso, muitas vezes são desvalorizados durante toda a carreira. "Com a longevidade conquistada, [...] pensa-se que o fazer docente não pode ser reduzido ao prazer quando se sabe, por observação, que a proximidade da velhice causa inquietação às pessoas" (RIBEIRO; SMEHA, 2009, p. 191).

A definição da função docente deve ser compreendida a partir do exercício da atividade profissional, sendo que ela se desenvolve no dia a dia escolar, na vida social e profissional (NUÑES, et al., 2013). 


\section{APOSENTADORIA}

A aposentadoria foi embutida no fim do século XIX nos países industrializados como forma de assegurar o sustento de trabalhadores mais velhos em seus últimos anos de vida, contudo, eram poucos que chegavam a idade exigida de 70 anos, a partir daí a situação modificou-se em diversos aspectos desde o que era considerado esmola e o que é um direito do trabalhador, a expectativa de vida aumentou bem como a imagem de velho e doente não se sustenta mais (FONTOURA; DOLL; OLIVEIRA, 2015).

De acordo com Soares (2002, p. 36, grifos do autor) ao aposentar-se o indivíduo vivencia a inatividade, ou seja, necessita lidar com as perdas ocasionando conflitos com sua capacidade laboral e a imposição determinada pela sociedade de que o aposentado "não precisa fazer nada", sendo que este conflito se repete em casa, pois ele passa a estar mais tempo nessa condição e desempenhando os papéis de pai, esposo e avô, o que anteriormente não acontecia devido suas obrigações trabalhistas e seu papel de provedor que visava o sustento da família (SOARES, 2002).

O desligamento das tarefas laborais designado pela aposentadoria pode ser uma das perdas mais significativas da vida dos indivíduos, visto que dela podem derivar outras perdas relacionadas à diminuição da renda familiar e a ansiedade diante do vazio gerado pela falta do trabalho (FRANÇA, 1999). Além disso, Soares, et al. (2007) diz que a aposentadoria afeta todas as pessoas que rodeiam o indivíduo que está vivenciando este momento, porque o papel de trabalhador já não existe mais, porém os outros papéis desempenhados pelo indivíduo podem sofrer alterações no que dizem respeito a sua convivência diária.

Deste modo, a maneira com que o indivíduo vive a aposentadoria é influenciada pela sua história de vida, suas relações com a sociedade e pelo lugar que o papel de seu trabalho ocupava em sua vida, além disso, outro quesito que é levado em consideração diz respeito à forma como o indivíduo encara as perdas e as mudanças (DEBETIR, 2011).

Neste sentido, a preparação para este afastamento é fundamental para abrandar os impactos, pois "grandes mudanças trazem novos horizontes e quebras de paradigmas capazes de deixar fluir na mente humana outros caminhos, outros meios de se chegar a um lugar de sucesso", apesar disso os indivíduos são resistentes as alterações, por isso quando os indivíduos não se preparam para a aposentadoria, se limitam a viver (CAMBOIM, et al., 2011, p. 54).

Assim, "a aposentadoria é um período de reestruturação da atividade e valores" (ROMANINI; XAVIER; KOVALESKI, 2005, p. 379), e, levando em conta estes apontamentos referentes ao envelhecimento, final de carreira, e, consequentemente a aposentadoria, foram pesquisados os aspectos positivos e negativos decorrentes do processo de aposentadoria, os pontos de maior mudança e o significado que a aposentadoria representa aos professores aposentados mediante entrevistas realizadas com quatro sujeitos.

\section{PROCEDIMENTOS METODOLÓGICOS}

O presente artigo consiste em uma pesquisa qualitativa, que segundo Strieder (2009) é a modalidade de pesquisa que utiliza distintas técnicas interpretativas para descrever, codificar, esclarecer e compreender os vários elementos de um acontecimento ou problema de pesquisa sempre em torno de um sistema complexo de significados.

Trata-se de uma pesquisa de campo, caracterizada como exploratória e descritiva, pois, segundo Gil (2002), a pesquisa exploratória tem como objetivo principal o aprimoramento de ideias, e a descritiva possui como finalidade a descrição das características de determinada população ou de determinado fenômeno. 
Foram entrevistados quatro sujeitos, os quais dispuseram-se a participar mediante convite. Para consignar o número de casos foi empregada a sugestão de Gil (2002), que indica que sejam utilizados de quatro a dez casos. Os participantes da pesquisa são quatro professores, sendo dois homens e duas mulheres, aposentados à mais de dois anos, na faixa etária entre 58 à 66 anos, professores do ensino fundamental e médio, os quais ministraram aula em uma cidade da região norte do Rio Grande do Sul.

Como instrumento de pesquisa, foi utilizado uma entrevista com roteiro semiestruturado com perguntas abertas relacionadas à aposentadoria. As entrevistas foram realizadas na residência de cada participante, de forma individual, com duração aproximada de trinta minutos, tendo sido utilizado gravador, com autorização dos entrevistados.

Antes de cada entrevista, foi apresentado e assinado pelos participantes o Termo de Consentimento Livre e Esclarecido e o Termo de Autorização de Uso de Gravação de Voz. A análise dos dados foi realizada de acordo com Bardin (2011), sendo realizada análise de conteúdo.

\section{APRESENTAÇÃO E ANÁLISE DOS DADOS}

Professor A: homem, 60 anos, casado, reside com a esposa, aposentado a 2 anos, começou a carreira em 1975, incentivado pelos pais, quis aposentar-se quando completou o tempo, voltou a dar aulas após a aposentadoria.

Professor B: homem, 58 anos, viúvo, reside com o neto, aposentado a 3 anos, começou a carreira em 1980, incentivado pela esposa, quis aposentar-se quando completou o tempo, não voltou a dar aula após a aposentadoria.

Professora C: mulher, 61 anos, casada, reside com o esposo, aposentada a 13 anos, começou a carreira em 1976, com iniciativa própria por ser a melhor opção na época, quis aposentar-se quando completou o tempo, não voltou a dar aula após a aposentadoria.

Professora D: mulher, 66 anos, casada, reside com o esposo, aposentada a 22 anos, começou a carreira em 1965, com iniciativa própria por ser um sonho, quis aposentar-se quando completou o tempo, não voltou a dar aula após a aposentadoria.

Por meio da análise de conteúdo das entrevistas, visando atender aos objetivos da pesquisa, optou-se pela classificação em categorias temáticas. A $1^{\text {a }}$ categoria pretende entender o significado que a aposentadoria representa para os sujeitos da pesquisa; a $2^{\mathrm{a}}$ procurou investigar quais foram os fatores de maior mudança após a aposentadoria, e por fim, a $3^{a}$ categoria visa pesquisar os aspectos positivos e negativos da aposentadoria na percepção dos sujeitos da pesquisa.

\section{SIGNIFICADO DA APOSENTADORIA}

Os quatro entrevistados afirmaram que a aposentadoria possibilita o cuidado de suas coisas particulares, fazer coisas que gostam, passear, viajar, ter liberdade, assim, o professor A disse que vê a aposentadoria "como uma diversão para aproveitar o resto da vida da forma que cada um deseja", demonstrando que sente-se feliz, porque está vivendo da forma que sempre quis.

Neste sentido, Zanelli; Silva; Soares (2010, p. 37) dizem que a qualidade de aposentado traz consigo a capacidade e a possibilidade de realizar de forma consciente, "o livre arbítrio", ou seja, o aposentado pode escolher vivenciar momentos tanto de aprendizado quanto de diversão, do mesmo modo que pode passar mais tempo com as pessoas que lhe são importantes. 
A professora $D$, disse que a aposentadoria significa estar livre, poder fazer as coisas sem pressa, sem estar presa a horários e que "os aposentados também podem curtir a vida", o que vai de acordo com Rodrigues (2000, p. 28) que diz acerca da aposentadoria que "alguns a vivem como um tempo de "liberdade", de "desengajamento profissional", de "possibilidade de realizações", de "fazer aquilo que não teve tempo de fazer" durante a vida ativa, de "aproveitar a vida", de "não ter mais patrão, horários obrigatórios" etc., [...]".

Para o professor B a aposentadoria remete para o momento de descansar, viajar, fazer coisas que se gosta, "é poder desfrutar de um tempo para descansar após tantos anos de dedicação a profissão". Assim, como aposentado, o sujeito tem a possibilidade de refletir sobre suas convivências, afazeres e sobre os seus interesses, "de modo que o que não foi possível alterar anteriormente em virtude da rotina exacerbada de trabalho passa a ser plausível nesta etapa da vida" (ZANELLI; SILVA; SOARES, 2010, p. 37), pois por vezes as próprias necessidades são adiadas, da mesma forma que as relações e até mesmo a "própria felicidade", por isso surge a importância de destinar o tempo ao que acredita-se essencial (ZANELLI; SILVA; SOARES, 2010).

Já a professora $\mathrm{C}$ disse não sentir-se aposentada, pois ela continua trabalhando e tendo atividades rotineiras "por continuar trabalhando ainda não me sinto aposentada de fato, pois na verdade só mudou o local", embora sinta-se com os horários mais flexíveis. Sobre isso Costa (2009, p. 34) diz que a aposentadoria não deve "ser vista como o fim dos projetos, mas sim, como um recomeço“, por isso é necessário reestruturar a identidade, resgatando outros afazeres, que podem, "propiciar mais prazer do que anteriores, estabelecer novos laços afetivos, descobrir ou redescobrir desejos, enfim, ter novos projetos de futuro" (COSTA, 2009, p. 34).

Neste sentido, Zanelli; Silva; Soares (2010) afirmam que o fato de o aposentado desligarse de sua vida laboral não remete ao término definitivo das atividades, pois os esforços físicos e psíquicos permanecem ao longo de toda a vida.

Deste modo, é importante que o sujeito estabeleça novas formas de obter satisfação com a aposentadoria, substituindo os estímulos antes gerados pelo trabalho por novas formas de prazer, fazendo com que essa nova etapa seja tão satisfatória quanto as experiências vivenciadas no período laboral, possibilitando o desenvolvimento pessoal, a auto-estima e desmistificando o juízo de que só se obtém satisfação por meio do trabalho (SOARES, et al., 2007).

\section{FATORES DE MAIOR MUDANÇA APÓS A APOSENTADORIA}

De acordo com a Classificação Brasileira de Ocupações (CBO) na descrição sumária acerca da profissão, o professor prepara e ministra aulas, tanto em escolas públicas quanto privadas, por meio da comunicação e expressão, sendo que as aulas podem ser teóricas ou práticas, efetuam registros burocráticos e pedagógicos, participam na elaboração do projeto pedagógico, planejam o curso, a disciplina e avaliam o processo de ensino-aprendizagem conforme as diretrizes educacionais. Além disso, atuam em reuniões administrativas e pedagógicas, organizam eventos e atividades sociais, culturais e pedagógicas (BRASIL, 2010).

Neste sentido, a professora C disse "minha rotina era em torno de preparar aulas, pesquisas, atividades extra-classe" e a professora D afirmou "na verdade, minha rotina era toda em torno da aula, diários, planos de aula e planos para o ano letivo inteiro", levando em conta a exigência que a carreira de professor demanda, Antunes (2014, p. 30) diz que "é pertinente observar que a carga horária excessiva de trabalho é considerada como prejudicial ao individuo, tanto pelas conseqüências que ocasiona em sua saúde quanto pela restrição de envolvimento pessoal em outros contextos". 
Com isso, a maior mudança remete sem dúvidas à rotina, todos os sujeitos entrevistados sinalizaram como ponto de maior transformação a alteração da rotina, pois depois da aposentadoria obtiveram mais tempo pra ficar com a família, para fazerem atividades que gostam e desfrutar do tempo livre, como a professora D disse "tive liberdade pra viver", a professora $\mathrm{C}$ afirmou que a rotina foi o ponto de maior mudança, visto que "antes eram 40 horas semanais na escola com os alunos e agora como trabalho no próprio negócio posso ser flexível com os horários".

Debetir (2011, p. 45) diz que "para alguns a aposentadoria é bem assimilada e, às vezes, até propiciadora de um renascer", pois surge a possibilidade de se realizar os desejos e as vontades diante do tempo disponível. No mesmo sentido, a aposentadoria está "associada à expectativa de exercer com mais intensidade atividades lúdicas, de ter uma vida menos cansativa e estressante, de dedicar-se mais à família" (ZANELLI, 2012, p. 331).

Dito isso, cabe destacar que todos os professores entrevistados têm atividades diárias, ou seja, uma professora e um professor trabalham em seus próprios negócios, ajudando esposo e filha respectivamente, o terceiro professor trabalha produzindo verduras e frutas para o consumo familiar, e, a outra professora faz serviço voluntário para preencher seu tempo e diz que é um trabalho gratificante poder ajudar o próximo. Frente à isso, a aposentadoria

[...] é vivida como um momento de realização, um direito adquirido pelos esforços durante o período dedicado às atividades laborais. Pessoas nessa perspectiva constroem suas identidades baseadas não apenas no papel profissional, mas também em outras fontes de engajamento, outras motivações e papéis sociais. A aposentadoria é vivida como um novo período, voltado para atividades que podem proporcionar prazer e autorrealização. [...] Nessa condição, a pessoa pode se dedicar a atividades de assistência ou de colaboração ativa em entidades beneficentes ou à própria família (ZANELLI, 2012, p. 333).

Assim, a mudança na rotina envolve a reestruturação do tempo de convivência entre os membros da família, das funções exercidas, bem como dos ambientes ocupados pelos aposentados (ANTUNES, SOARES, MORÉ, 2015).

\section{ASPECTOS POSITIVOS E NEGATIVOS DA APOSENTADORIA}

Os aspectos positivos da aposentadoria na percepção dos quatro sujeitos da pesquisa condizem entre si, pois todos apontaram o fato de fazer o que gostam, além de possuírem horários de fácil manejo, bem como podem ficar mais tempo com a família, o professor A diz "posso fazer diariamente o que eu gosto, posso trocar horários, sair e voltar sem hora marcada, passar mais tempo com a família, enfim, estou muito feliz", a professora D afirma "eu só vejo aspectos positivos, por exemplo não estar presa aos horários da escola, ter liberdade para viver sem estar com um compromisso marcado, ficar mais tempo com a família".

Neste sentido, conforme Antunes; Soares; Moré (2015, p. 438) a relação familiar na aposentadoria tende a ter características de solidariedade e ajuda, pois o "contexto familiar ocupa um lugar central na vida do aposentado e é uma das suas principais referências e espaços de pertencimento neste período". Além disso, a característica dos vínculos estabelecidos na família, bem como o acolhimento e apoio demonstrado pelos demais, são "elementos estruturantes das ações e projetos que serão executados pelo aposentado nesse período da vida" (ANTUNES; SOARES; MORÉ, 2015, p. 438), que vai de acordo com a fala do professor B "para mim, são de desfrutar de um tempo para fazer o que gosto, ter horários flexíveis e ter mais tempo para passar com a família".

Deste modo, Zanelli; Silva; Soares (2010) trazem que a valorização do tempo livre 
possibilita ao aposentado fazer o que anseia, diante da redução da carga horária destinada quase que exclusivamente ao trabalho, além disso, surge a possibilidade de valorizar e priorizar o convívio, a amizade, o amor, a autorrealização, visto que a aposentadoria

\begin{abstract}
[...] é um momento propicio para realizar mudanças pessoais profundas, que possam focar atenção afetiva para tudo aquilo que de fato importa ou é relevante. É um momento oportuno para resgatar aspectos simples e importantes da vida, mas que fazem diferença significativa para a busca da felicidade humana (ZANELLI; SILVA; SOARES, 2010, p. 37).
\end{abstract}

As transformações na rotina familiar são vistas como positivas, uma vez que remetem ao fortalecimento das relações parentais, provenientes da possibilidade de maior dedicação aos filhos e companheiros, sendo guiada pelo diálogo e cordialidade (DEBETIR, 2011). Destarte, a aposentadoria é uma das principais mudanças que ocorrem na vida adulta, a qual implica em várias alterações na vida do indivíduo e no ambiente ao qual ele se encontra, por isso "a família se constitui um dos principais espaços que serão habitados pelo individuo aposentado" (ANTUNES, 2014, p. 8).

Já, com relação aos aspectos negativos os entrevistados, os professores A e B relatam como pontos negativos o fato de por vezes sentirem falta dos alunos e dos colegas de profissão, conforme a fala do professor A "sinto falta dos alunos, mas pra compensar isso converso bastante com as pessoas, e vou levando essa falta com leituras", o professor B também relata como ponto negativo a mesma falta, dizendo que "às vezes sinto falta da convivência diária com os alunos e os colegas de profissão", além disso, comentaram questões pertinentes ao salário o qual poderia ser maior e ser pago de forma integral e não parcelada, de acordo com a fala do professor B "nunca tinha me passado pela cabeça que depois de aposentado teria que receber o meu salário parcelado em 3,4 e até 8 vezes como venho recebendo há 9 meses, essa situação estabelecida pelo governo estadual é humilhante e desesperadora". Porém, ambos recomendam a aposentadoria aos colegas e sentem-se livres e satisfeitos com a aposentadoria.

Acerca disso, Zanelli (2012, p. 331) diz que uma das perdas advindas juntamente com a aposentadoria se encontra a preocupação "com os vínculos de amizade do ambiente laboral", visto que a convivência diária com os colegas de profissão acaba criando vínculos que o sujeito não sabe se serão mantidos ou interrompidos juntamente com a aposentadoria.

Em contra partida, as professoras $C$ e $D$ não perceberam nenhum ponto negativo apenas ganhos, sentem-se livres e realizadas com a aposentadoria, neste sentido, percebe-se a presença do sentimento de dever cumprido e a possibilidade de usufruir de momentos com horários flexíveis e aproveitar a companhia da família.

\title{
CONSIDERAÇÕES FINAIS
}

As entrevistas com os professores trouxeram à tona a importância de ter um tempo livre e horários flexíveis, bem como o cuidado em se fazer presente na família. Os professores demonstraram que a carreira e a rotina escolar os sobrecarregava e os limitava no exercício de seus papéis fora da escola, pois sempre estavam ocupados com atividades profissionais, deixando de lado seus gostos, suas famílias e seu lazer, privando-se de sua liberdade.

A visão dos entrevistados sobre a aposentadoria é de que a mesma permite a realização de atividades diversas, a companhia, a presença e a participação na rotina da família, além de descanso e satisfação em usufruir deste momento, que é visto por eles como um período para aproveitar e viver a vida, além de vivenciar o sentimento de dever cumprido diante da carreira profissional. 
A partir da aposentadoria o indivíduo tem a possibilidade de refletir sobre seu convívio diário tanto com amigos quanto com parentes, cônjuges e filhos, além de propiciar a realização de afazeres particulares e seus interesses específicos, o que antes não era possível e habitualmente era adiado em virtude da rotina acentuada de trabalho. Deste modo, a aposentadoria traz consigo o recomeço e a necessidade de reestruturação da própria identidade e de seus novos papéis que são desempenhados.

O trabalho é substituído por novas fontes de prazer e atividades, as quais tendem a preencher o espaço que antes era dedicado exclusivamente ao trabalho, sendo geralmente direcionadas à família o que os motiva e os deixa satisfeitos diante do sentimento de poder colaborar e auxiliar nas atividades rotineiras da família, e até mesmo realizar trabalhos voluntários, neste sentido, a aposentadoria acabou fortalecendo os vínculos familiares e o sentimento de pertencimento direcionado ao papel de membro da família, enriquecendo os vínculos parentais, sendo que a família é o maior ponto de referência do sujeito aposentado.

Por fim, cabe destacar que esta pesquisa tem caráter qualitativo e não se almeja generalizar os resultados. Deste modo, sugere-se a realização de novos estudos relacionados à forma de como professores aposentados vivenciam o afastamento do trabalho em virtude da aposentadoria, a diferenciação entre os sexos, bem como dos que realizam atividades e dos que não tem comprometimento com trabalho, além da distinção dos que aposentaram-se por tempo de serviço e dos que aposentaram-se por idade, cabe ainda expandir a pesquisa com relação a outras profissões e demais categorias, do mesmo modo em famílias sem filhos.

\section{REFERÊNCIAS BIBLIOGRAFICAS}

ANTUNES, M. H. Entre "o mito do pijama" e o "projeto de ser feliz": as repercussões da aposentadoria na dinâmica relacional familiar na perspectiva do casal. Dissertação (mestrado) - Universidade Federal de Santa Catarina, Centro de Filosofia e Ciências Humanas, Programa de Pós-Graduação em Psicologia, Florianópolis, 2014. Disponível em: https://repositorio.ufsc. $\mathrm{br} / \mathrm{bitstream} /$ handle/123456789/123210/326768.pdf?sequence=1 Acesso em: novembro de 2016.

ANTUNES, M. H.; SOARES, D. H.; MORÉ, C. L. O. O. Repercussões da Aposentadoria na Dinâmica Relacional Familiar na Perspectiva do Casal. Psico, Porto Alegre, v. 46, n. 4, pp. 432-441, 2015. Disponível em: http://pepsic.bvsalud.org/pdf/psico/v46n4/04.pdf Acesso em: novembro de 2016

BARDIN, L. Análise de conteúdo. ed. rev. e atual. São Paulo: Edições 70, 2011.

BRASIL, Ministério do Trabalho e Emprego. Classificação Brasileira de Ocupações: CBO. 3 ed $^{\text {a }}$. Brasília: Secretaria de Políticas Públicas de Emprego, 2010. Disponível em: www. mtecbo.gov.br/cbosite/pages/download?tipoDownload=1 Acesso em: junho de 2016.

CAMBOIM, V. S. C.et al. Aposentadoria, o desafio da segunda metade da vida: estudo de caso em uma agência bancária. Revista Gestão Organizacional. v. 4, n. 1, art. 3, 2011.

Disponível em: http://www.spell.org.br/documentos/ver/2134/aposentadoria--o-desafiodasegunda-metade-da-vida--estudo-de-caso-em-uma-agencia-bancaria Acesso em: abril de 2016

COSTA, A. B. Projetos de futuro na aposentadoria. Dissertação (Mestrado em Psicologia), Programa de Pós-Graduação em Psicologia, Centro de Filosofia e Ciências Humanas, Universidade Federal de Santa Catarina. Florianópolis, 2009. Disponível em: https://repositorio. ufsc. $\mathrm{br} / \mathrm{bitstream} / \mathrm{handle} / 123456789 / 92864 / 274063$. pdf?sequence=1\&isAllowed=y Acesso em: novembro de 2016.

DEBETIR, E. Aposentadoria - Oportunidade de Realizar Projetos e/ou Momento de Crise? 
Revista de Carreiras e Pessoas. v. 1, n. 2, 2011. Disponível em: http://www.spell.org.br/ documentos/ver/40383/aposentadoria-----oportunidade-de-realizarprojetos-e-ou-momentode-crise- Acesso em: abril de 2016.

FERRARI, M. A. C. O envelhecer no Brasil. O Mundo da Saúde. São Paulo, v. 23, n. 4,1999. Disponível em: http://bases.bireme.br/cgi-bin/wxislind.exe/iah/online/?/sisScript=iah/ iah $. x i s \& s r c=g o o g l e \& b a s e=$ LILACS\&lang=p\&nextAction=Ink\&exprSearch=239841\&indexSear ch=IDAcesso em: maio de 2016.

FRANÇA, L. Preparação para a aposentadoria: desafios a enfrentar. In: VERAS, Renato. Terceira Idade: Alternativas para uma sociedade em transição. Rio de Janeiro: Relume Dumará, 1999.

FONTOURA, D. S.; DOLL, J.; OLIVEIRA, S. N. O Desafio de Aposentar-se no Mundo Contemporâneo. Educação \& Realidade. Porto Alegre, v. 40, n. 1, 2015. Disponível em: http:// www.seer.ufrgs.br/index.php/educacaoerealidade/article/view/45774/32228 Acesso em: abril de 2016

GIL, A. C. Como Elaborar Projetos de Pesquisa. 4. ed. São Paulo: Atlas, 2002.

HUBERMAN, M. O ciclo de vida profissional dos professores. In: NÓVOA, A. (Org.). Vidas de professores. Porto: Porto Editora, 1992.

LIBÂNEO, J. C. Adeus professor, adeus professora? Novas exigências profissionais e profissão docente. 7.ed. São Paulo: Cortez, 2003.

MAGALHÃES, M. O.; BENDASSOLLI, P. F. Desenvolvimento de carreiras nas organizações. In: BORGES, Livia de Oliveira.; MOURÃO, Luciana (Orgs.). O Trabalho e as organizações: atuações a partir da psicologia. Porto Alegre: Artmed, 2013.

MARX, K. A dialética do trabalho: escritos de Marx e Engels. Ricardo Antunes (Org.). São Paulo: Expressão Popular, 2004.

MOREIRA, J. O. Imaginários sobre aposentadoria, trabalho, velhice: estudo de caso com professores universitários. Psicologia em Estudo. vol.16. n. 4. Maringá, 2011. Disponível em: http://www.scielo.br/scielo.php?script=sci_arttext\&pid=S141373722011000400005Acesso em: abril de 2016.

MUTCHNIK, V. I.; TREVISAN, L. Carreira e Senioridade. Revista Administração em Diálogo. N. 13, v. 2, 2009.

NÉRI, A. L. Contribuições da psicologia ao estudo e à intervenção no campo da velhice. RBCEH - Revista Brasileira de Ciências do Envelhecimento Humano. Passo Fundo-RS, 2004. Disponível em: http://www.upf.br/seer/index.php/rbceh/article/view/46/55Acesso em: março de 2016

NUÑES, I. B.; et al. O tempo e o profissionalismo docente: o caso de professores do ensino médio. Universidade Federal do Rio Grande do Norte - UFRN. Observatório da Vida do Estudante Universitário - Comperve, 2013. Disponível em: http://www.comperve.ufrn.br/ conteudo/observatorio/uploads/publicacoes/artigos_050220130 82758.pdf Acesso em: junho de 2016.

RIBEIRO, L. J. B.; SMEHA, L. N. O que me leva a continuar? A permanência do professor universitário aposentado no exercício de sua profissão. Revista Disc. Scientia. v. 10, n. 1. Ciências Humanas. Santa Maria-RS, 2009. Disponível em: http://sites.unifra.br/Portals/36/ Artigos\%202009\%20CH/13.pdf Acesso em: junho de 2016.

RODRIGUES, N. C. Aspectos sociais da aposentadoria. In Schons, C. R. \& Palma, L. S. (Orgs.), Conversando com Nara Costa Rodrigues: sobre gerontologia social. Passo FundoRS, 2000. 
ROMANINI, D. P.; XAVIER, A. A. P.; KOVALESKI, J. L. Aposentadoria: período de transformações e preparação. Revista Gestão Industrial. V. 01, n. 03, 2005. Disponível em: http://www.abepro.org.br/biblioteca/ENEGEP2004_Enegep0404_0797.pdf Acesso em: maio de 2016.

SOARES, D. H. P. A escolha profissional: do jovem ao adulto. São Paulo: Summus, 2002.

SOARES, D. H. P. et al. Aposenta-Ação: programa de preparação para aposentadoria. Estudos Interdisciplinares sobre o Envelhecimento. Porto Alegre, 2007. Disponível em: http:// www.seer.ufrgs.br/index.php/RevEnvelhecer/article/view/4984/2853 Acesso em: março de 2016.

SCHEIN, E. H. Identidade profissional: como ajustar suas inclinações a suas opções de trabalho. São Paulo: Nobel, 1996.

SPIRDUSO, W. W. Dimensões físicas do envelhecimento. São Paulo: Editora Manole, 2005.

STRIEDER, R. Diretrizes para Elaboração de Projetos de Pesquisa. Caderno 3 da série Metodologia do trabalho científico da Unoesc. ed. Joaçaba: Unoesc, 2009.

TARDIF, M.; RAYMOND, D. Saberes, tempo e aprendizagem do trabalho no magistério. Educação e Sociedade. v. 21, n. 73. Campinas, 2000. Disponível em: http://www.scielo.br/pdf/ es/v21n73/4214.pdf Acesso em: junho de 2016.

UNESCO, Pesquisa Nacional. O Perfil dos professores brasileiros: o que fazem, o que pensam, o que almejam. São Paulo: Moderna, 2004. Disponível em: http://unesdoc.unesco. org/images/0013/001349/134925por.pdf Acesso em: junho de 2016.

ZANELLI, J. C.; SILVA, N.; SOARES, D. H. P. Orientação para aposentadoria nas organizações de trabalho: construção de projetos para o pós-carreira. Porto Alegre: Artmed, 2010.

ZANELLI, J. C. Processos Psicossociais, Bem-Estar e Estresse na Aposentadoria. Revista Psicologia: Organizações e Trabalho. vol. 12 num. 3, 2012. Disponível em: http://pepsic. bvsalud.org/pdf/rpot/v12n3/v12n3a07.pdf Acesso em: novembro de 2016.

ZIMERMAN, G. I. Velhice: aspectos biopsicossociais. Porto Alegre: Artmed, 2000. 